\title{
IRIDOSTASIS AND DOUBLE SPHINCTERO-IRIDOTOMY WITH CATARACT EXTRACTION*†
}

\author{
BY \\ R. P. SARDA, M. R. JAIN, AND C. J. S. AHLUWALIA \\ Department of Ophthalmology, SMS Medical College and Hospital, Jaipur, Rajasthan, India
}

THIS modification of our earlier one-stage operation for cataract associated with glaucoma (Nagpaul, Charan, and Sarda, 1966) has certain advantages over the previous technique of cataract extraction with iridencleisis (Fig. 1, opposite):

(1) The updrawn pupil which was invariably present is almost completely avoided. Hughes (1959) and Hughes, Kazdan, Brackup, and Marinakos (1963) described a sphincterotomy at the 6 o'clock position, incising the iris margin about $2 \mathrm{~mm}$. radially to counteract the updrawn pupil which followed iridencleisis. By this technique, however, there may be too little response to miotics if required postoperatively, and also the lower pupillary margin becomes slightly irregular with a poor cosmetic effect.

(2) Miotics can be freely used without impairment of vision.

(3) The high incidence of capsular rupture observed in our previous series is avoided because the double sphinctero-iridotomy gives a wider pupil so that lens extraction is easier.

(4) The presence of a trachomatous opacity on the upper third of the cornea, which is very common in Rajasthan, does not impair the visual acuity when this technique is used.

(5) In cases of microcornea with cataract and glaucoma good results may be obtained.

\section{Material and Methods}

36 consecutive cases of glaucoma associated with mature or nearly mature cataract were treated. The visual acuity ranged from counting fingers at $3 \mathrm{~m}$. to good perception of light with doubtful projection. There were some cases of subacute or chronic closed-angle glaucoma with operable cataract, and some of chronic simple glaucoma with associated immature or mature cataract.

Preparation.-After visual assessment and measurement of ocular tension ( $\mathrm{mm}$. Hg Schiötz), the preoperative preparation is the same as in our previous cases of cataract with glaucoma. Miotics are instilled and oral glycerol and Diamox administered to lower the intra-ocular pressure, which is recorded twice a day. On the day of operation $4 \mathrm{oz}$. 50 per cent. glycerol in normal saline is administered orally 2 hours before the operation. Local anaesthesia is used in all cases.

Operation.-Two separate incisions are made (Nagpaul and others, 1966), one for iridostasis and the other for lens extraction. At $120^{\prime}$ clock, $6 \mathrm{~mm}$. from the limbus the conjunctiva is incised and reflected over thecornea as for iridencleisis. The dissected vessels are cauterized with a thermo-cautery and a keratome incision is made $2 \mathrm{~mm}$. behind the limbus. On gently pressing the posterior lip of the section, the iris presents itself at the section in most cases, and it is then pulled out with the iris forceps.

If the iris does not present at the section, the iris forceps are introduced into anterior chamber. Air is injected into the anterior chamber through the same section, the conjunctiva is reposited over the protruding iris, and a continuous $6 / 0$ black silk suture is inserted (Fig. 2, opposite).

The air in the anterior chamber makes the subsequent knife-section for cataract extraction easier and also helps to stop any oozing of blood. After a corneo-limbal cataract knife section, an incision of about 1 to $1.5 \mathrm{~mm}$. is made radially with de Wecker's scissors both in the sphincter and in a little portion of iris at the periphery at about 11 to 1 o'clock (this is the double sphinctero-iridotomy).

After the iris is reposited, the pupil falls down and becomes almost central. Three corneo-limbal sutures are introduced and the lens is extracted in the classical way. The sutures are tied and air is injected into the anterior chamber (Fig. 3, opposite).

\footnotetext{
* Received for publication May 1, 1967.

† Address for reprints: 39 Hospital Rd., Jaipur, India.
} 


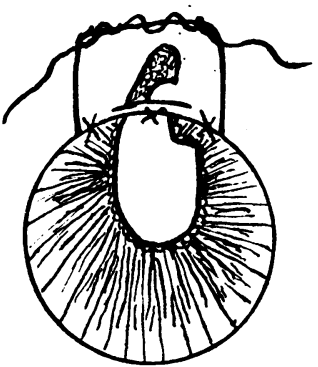

FIG. 1.-Iridostasis.

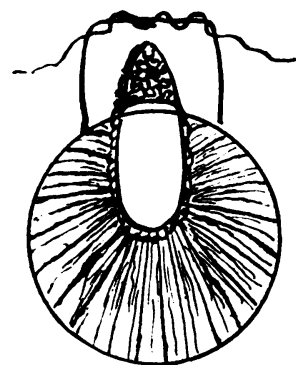

Fig. 2.-Iridostasis with doublesphinctero-iridotomy and cataract extraction.

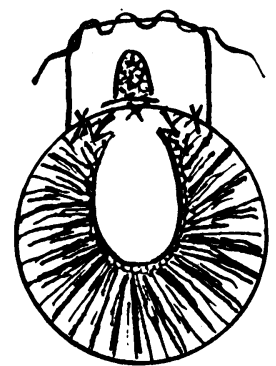

Fig. 3.-Cataract with iridencleisis (showing updrawn pupil).
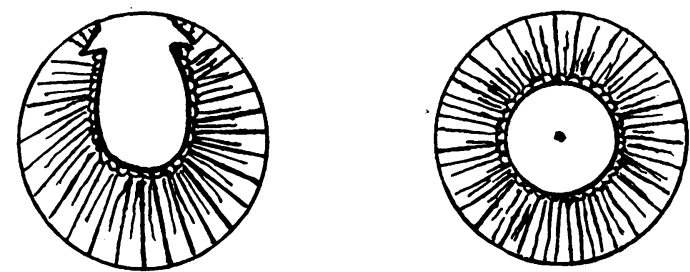

Figs 4 and 5.-Comparative level of lower pupillary margin in normal pupil and pupil subjected to sphinctero-iridotomy.

Observations and Discussion

Complications.-The operative and postoperative complications in our present and previous series is given in Table $\mathrm{I}$, which shows a marked reduction of complications in the later series apart from that of incidental trauma to the lens. Perforation of the lens occurred in one case when we failed to retain air in the anterior chamber afteriridostasis, and in two other cases at the beginning of the series during the sphinctero-iridotomy. This complication was completely avoided in later cases by lifting the iris away from the lens while the sphinctero-iridotomy was performed.

Comparison With Previous Series

\begin{tabular}{l|l|c|c}
\hline \multicolumn{1}{c|}{ Complications } & $\begin{array}{c}\text { Present Series } \\
\text { Iridostasis with } \\
\text { Double Sphinctero- } \\
\text { iridotomy } \\
\text { (per cent.) }\end{array}$ & $\begin{array}{c}\text { Previous Series } \\
\text { Iridencleisis } \\
\text { (Nagpaul, Charan, } \\
\text { Sarda, 1966) } \\
\text { (per cent.) }\end{array}$ \\
\hline \multirow{5}{*}{ Operative } & $\begin{array}{l}\text { Extracapsular } \\
\text { Incidental trauma to lens }\end{array}$ & $16 \cdot 7$ & 28 \\
& Vitreous loss & $8 \cdot 3$ & 14 \\
Postoperative & Involuntary iridectomy & $11 \cdot 0$ & 6 \\
& Persistent keratitis & $5 \cdot 5$ & 6 \\
& Delayed formation of anterior chamber & $5 \cdot 5$ & 12 \\
& Iris incarceration & $8 \cdot 3$ & 2 \\
\hline
\end{tabular}

The dilated pupil made intracapsular extraction much easier; the extracapsular operation was required in only five cases including the three cases of trauma to the lens already mentioned. Vitreous loss was much less than in our previous series but. was higher than the 5 per cent. reported by Arruga (1956) in uncomplicated cataract extraction. For this 
there were two reasons; in nearly 20 per cent. of our series the ocular tension was greater than $30 \mathrm{~mm}$. $\mathrm{Hg}$ and when extracapsular extraction was necessary we tried to remove the capsule completely in order to give useful vision. In three cases a little vitreous was lost when tags of capsule were being removed. Slight sectoral keratitis was noted at the first dressing in nearly 30 per cent. of cases but persisted in only two cases. The vision was not adversely affected since the pupil being almost central (Fig. 4), as compared with normal (Fig. 5), the lower pupillary area remained clear and the cosmetic effect was good.

In three cases the anterior chamber remained shallow for 4 to 10 days. In two of these acetazolamide helped to reform the chamber within 4 to 5 days, but the third required the application of indirect heat for 6 to 7 days.

Hyphaema was refractory but disappeared with iodine therapy within 3 to 4 days.

Control of Ocular Tension.- - Of the 36 cases (Table II), five did not attend for follow-up; of the other 31 cases, 28 (90 per cent.) had normal ocular tension (up to $22 \mathrm{~mm}$. $\mathrm{Hg}$ ). In two of the remainder miotic treatment was effective and the third was controlled by cyclodialysis.

TABLE II

OCular TENSION (PER CENT.)

\begin{tabular}{c|c|c|c}
\hline \multicolumn{2}{c|}{ Postoperative Ocular Tension } & Present Series & Previous Series \\
\hline Normal & $22 \mathrm{~mm}$. Hg Schiötz & $90 \cdot 5$ & $82 \cdot 2$ \\
\hline \multirow{2}{*}{ Raised } & Controlled with miotics & $\left.\begin{array}{r}6.3 \\
3.2\end{array}\right\} 9 \cdot 5$ & $\left.\begin{array}{r}3.6 \\
14.2\end{array}\right\} 17.8$ \\
\hline
\end{tabular}

Visual Acuity.-Since these patients were mostly in the chronic phase of acute or simple glaucoma with marked or moderate cupping, the visual gain was not as good as would be expected in cases of uncomplicated cataract, but it was much better than in our former series (Table III).

TABLE III

Visual ACUITY (PER CENT.)

\begin{tabular}{l|c|c}
\hline Visual Acuity & Present Series & Previous Series \\
\hline $6 / 60$ and above & 69.4 & 42 \\
$3 / 60$ to $5 / 60$ & 13.9 & 24 \\
Below $3 / 60$ & 11.0 & 26 \\
No useful vision & $5 \cdot 5$ & 8 \\
\hline
\end{tabular}

\section{Summary}

36 cases of cataract associated with various types of glaucoma have been surgically treated by a one-stage operation, iridostasis with double sphinctero-iridotomy with cataract extraction. The results are compared with those in a previous series of iridencleisis with cataract extraction. In the later series the complications are less, control of the tension is more successful, and the visual gain greater because of the almost central pupil.

Hughes, W. L. (1959). Amer. J. Ophthal., 48, 1.

\section{REFERENCES}

, Kazdan, M. S., Brackup, A. H., and Marinakos, C. (1963). Ibid., 56, 391.

Nagpaul, P. N., Charan, H., and Sarda, R. P. (1966). J. All-India ophthal. Soc., 14, 31. 